\title{
Low-Cost I-V Tracer for Photovoltaic Modules and Strings
}

\author{
Vicente Leite ${ }^{1}$, José Batista ${ }^{2}$ \\ School of Technology and Management \\ Polytechnic Institute of Bragança \\ Bragança, Portugal \\ ${ }^{1}$ avtl@ipb.pt, ${ }^{2}$ jbatista@ipb.pt
}

\author{
Faustino Chenlo \\ CIEMAT - Research Centre for \\ Energy, Environment and Technology \\ Madrid, España \\ faustino.chenlo@ciemat.es
}

\author{
João L. Afonso \\ Centro Algoritmi, Univ. Minho \\ Department of Industrial Electronics \\ Guimarães, Portugal \\ jla@dei.uminho.pt
}

\begin{abstract}
This paper presents new developments of a robust and low-cost instrument-less than $600 €$ - for monitoring and processing $\mathrm{I}-\mathrm{V}$ and $\mathrm{P}-\mathrm{V}$ characteristics of photovoltaic (PV) modules and high voltage strings. The characteristics can be traced on an oscilloscope or using a developed a LabVIEW application. It is a simple instrument because only fundamental electronic circuits are used. The equipment consists of a flexible configuration, developed from a previous work, based on a fast varying load based on a power MOSFET. The MOSFET was controlled by means of suitable gate-source voltage control signal in order to improve the tracing of $I-V$ and $P-V$ characteristics on an oscilloscope. The contribution of this work includes new developments of a previous I-V tracer in order to be use with high voltage strings and a low-cost DAQ monitoring system based on two applications developed in LabVIEW-one for PV modules and the other for PV strings. On the other hand, the robustness for high voltage strings was strongly improved in view of field tests for fault diagnosis analysis. Experimental results obtained with the new instrument are presented with modules and different strings available with voltages up to 1000 volt.
\end{abstract}

Keywords-PV Modules and Strings; I-V and P-V Characteristics; I-V Tracer; LabVIEW; Fault Diagnosis.

\section{INTRODUCTION}

Photovoltaic (PV) energy is booming and a widespread use of low power of distributed PV systems is now a reality because of the modularity of PV technology, which is used even for sizing high power PV plants. The growth of the annual market regarding PV industry is evident in many countries [1], [2]. Installations of PV modules around the world have been growing at a very high average annual rate and some could argue the $100 \mathrm{GW}$ mark worldwide has been passed [1]. According to the report [2], by 2030 the capacity of installed PV systems could be around $1082 \mathrm{GW}$ under an accelerated scenario, and $1845 \mathrm{GW}$ under the so called "paradigm shift scenario". Furthermore, by 2050 there could be over $4500 \mathrm{GW}$ of PV installed world-wide under this latest scenario [2]. Thus, it becomes evident that one can expect a very strong transformation and expansion of the PV industry sector over the coming decades.
In spite of their well known reliability, some PV modules degrade or even fail when operating outdoors for extended periods, and that can occur in a number of ways [3]. In the degradation diagnosis in PV cells of modules and strings, the Current-Voltage (I-V) characteristics are usually used, as well as parameters obtained from them, like short-circuit current $\left(I_{S C}\right)$, open-circuit voltage $\left(V_{O C}\right)$, maximum power $\left(P_{\max }\right)$ and fill factor $\left(\mathrm{FF}=P_{\max } / I_{S C} V_{O C}\right)$. On the other hand, the I-V characteristics can be monitored and the results used to investigate and to compare the actual power produced by modules under realistic operating conditions [4]. Thus, I-V characteristics are not only used by designers in power converter systems, but also in PV systems design, to make these systems more cost effective.

Photovoltaic modules are usually tested using electronic DC loads, which can vary the load resistance over the entire range in a very short time. However, the ones available on the market are often expensive. Anyway, by using quite simple and much cheaper circuits, it is also possible to build an electronic DC load taking advantage of a suitable operation of a power MOSFET, as described in [5] and [6]. In fact, a power MOSFET operating in the active region can be used as an electronic load to test PV modules [4] - [8]. Some simple and/or low-cost electronic circuits have been developed along this decade. In [9] simple and low-cost electronic circuits that facilitate the data acquisition of I-V characteristics of PV cells were proposed. The I-V characteristics of PV modules were measured in [10], with a swept method by charging a capacitor. This principle was used recently in [11] for in-door I-V curve trace of PV modules. In [4] it is reported the design of a low-cost measuring system used to monitor the I-V characteristics of PV modules. The system was previously developed in [12] and measures I-V characteristics of seven different modules sequentially by selecting a module through mechanical relays. Other set of relays are used to select a parallel combination of resistors used as resistive loads for a particular I-V pair of values. By using a combination of resistors, several resistances are achieved to measured I-V pairs. A more interesting electronic circuit, being a fast varying load, is presented in [8]. The circuit is based on a MOSFET operating in its linear region and the proposed circuit traces the I-V and $\mathrm{P}-\mathrm{V}$ characteristics of $\mathrm{PV}$ modules 
by quickly scanning the load by sweeping the $V_{G S}$ (gate to source voltage) of the MOSFET with a sinusoidal waveform. Other parameters are also provided. The power generated by the PV module is dissipated in a series power resistor.

In [5] an improved electronic circuit was presented to test PV modules by tracing their I-V and P-V characteristics and in [6] a LabVIEW application was developed using a low-cost DAQ system to enhance the functionalities and flexibility of the previous I-V tracer [5]. As in [8] it was based on a power MOSFET but the scanning voltage $\left(V_{G S}\right)$ was achieved in an innovative way in order to improve the I-V tracing on an oscilloscope. Moreover, galvanic isolation was introduced to prevent damage of data acquisition systems and to enable the circuit to be used in tests of PV strings. However, the robustness of the circuit with high power strings (above several hundreds of $\mathrm{W}$ ) the IGBT, even mounted on a heat sink, cannot stand such power in the active region for a long time (of the order of a few ms or less) because of the limits of the safe operating area. This problem requires an experienced operator and limits the voltage (power) of the string to be tested.

In this paper the new developments of the previous circuit [5] are presented aimed to improve the robustness of tracing I-V characteristics for high voltage strings in view of field tests for fault diagnosis analysis. The new instrument uses a combination of methods for this purpose. Furthermore, the low-cost DAQ system and the developed LabVIEW application [6], with virtual instruments and new functionalities, have allowed the enhancement of functionalities of the new I-V tracer which can now be used with high voltage PV strings.

\section{DESCRIPTION OF THE ELECTRONIC INSTRUMENT}

A general scheme of the proposed electronic circuit to test PV modules and strings is shown in Fig. 1 and a simplified scheme of the new instrument is shown in Fig. 2. It is based on the previous electronic circuit described in [5], where part of the original electronic circuit was replaced by a LabVIEW application.

In these figures, $V_{G S}$ is the gate-source voltage, $V_{P V}$ and $I_{P V}$ are the output voltage and current of the PV module or string, $I_{S C}$ is the short circuit current and $V_{O C}$ is the open circuit voltage, $V_{M P P}$ and $I_{M P P}$ are the voltage and current at the Maximum Power Point (MPP), $\mathrm{R}_{\mathrm{Vpv}}$ and $\mathrm{R}_{\mathrm{Ipv}}$ are measurement resistors for $V_{P V}$ and $I_{P V}$, and $R_{p}$ is the selectable power resistor for different measurement scales of $V_{P V}$.

For monitoring individual PV modules the power jumper of Fig. 1 must be in position A. The $\mathrm{I}-\mathrm{V}$ and $\mathrm{P}-\mathrm{V}$ tracing is achieved by using the MOSFET IRFP260N as an electronic fast continuous varying load, which principle of operation has been described in [5]. In this case a high voltage MOSFET or an IGBT can be used to trace the I-V and P-V characteristic of strings, but the power of the string is limited by the safe operating area of the power device, since it cannot stand a high power for more than some milliseconds. Thus, a combination of methods is proposed in this work. On the other hand, the continuous tracing of the $\mathrm{I}-\mathrm{V}$ and $\mathrm{P}-\mathrm{V}$ characteristics of individual modules or low voltage strings is achieved by using a MOSFET or an IGBT, respectively, as a fast varying load and, on the other hand, single tracing of

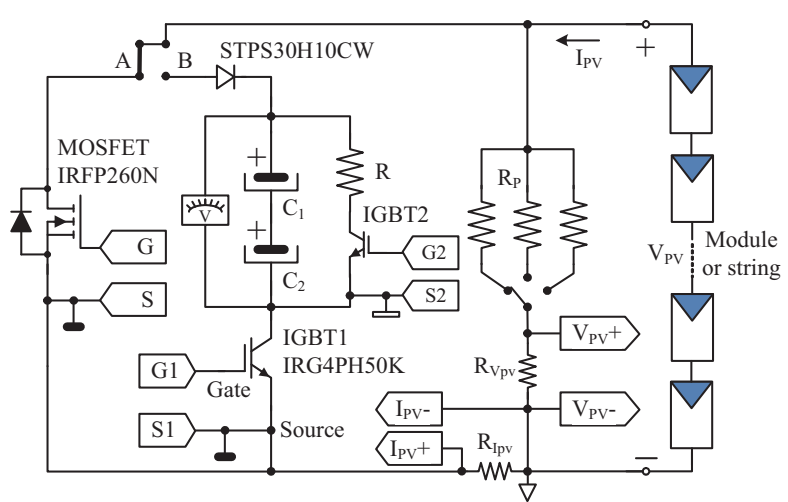

Fig. 1. Electronic circuit for $\mathrm{I}-\mathrm{V}$ and $\mathrm{P}-\mathrm{V}$ tracing of photovoltaic modules and strings.

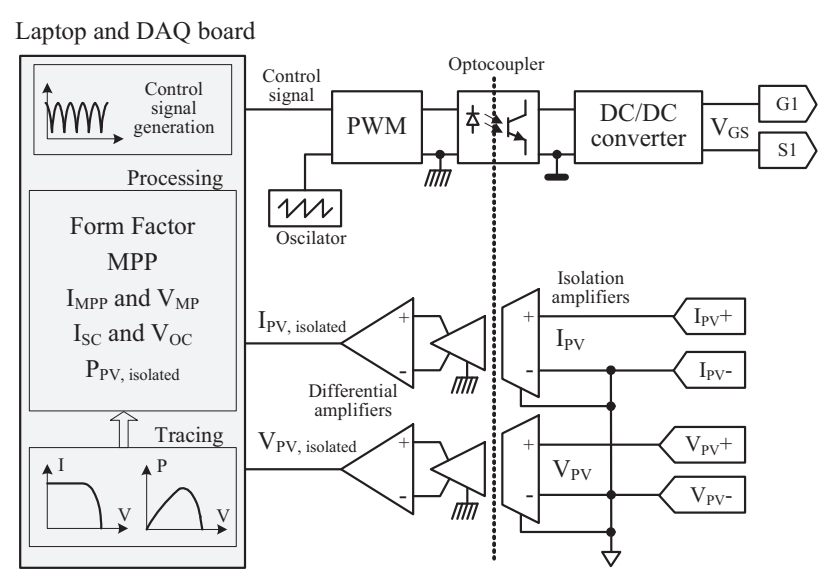

Fig. 2. Simplified scheme of the new proposed instrument.

high voltage strings is made by means of an IGBT and a capacitor as a capacitive load.

Thus, for monitoring high voltage PV strings the power jumper of Fig. 1 must be in position B. The IGBT1 IRG4PH50K works as an electronic switch supporting string voltages up to $1000 \mathrm{~V}$ and is used to charge the capacitors $\mathrm{C}_{1}$ and $\mathrm{C}_{2}$ in series because of the high voltages. These capacitors are used as a capacitive load to implement an I-V tracer as in the method of [10] and [11] but in this case for high voltage strings in field conditions. In order to obtain the $\mathrm{I}-\mathrm{V}$ and $\mathrm{P}-\mathrm{V}$ curves of the PV string and other parameters, the capacitors are connected to the string by means of the IGBT1. Assuming that the initial voltage of the capacitors is zero, the current established immediately after the switching on the IGBT1 is the maximum charging current and correspond to the short-circuit current of the string. As the voltage of the capacitors is increasing to $V_{O C}$ and the charging current is decreasing to zero, the operating point of the PV string moves from short-circuit to open-circuit operating point. During this period, current and voltage are sampled by a DAQ board or monitored on a digital oscilloscope and correspond to an I-V curve of the string. Then the power resistor $\mathrm{R}$ is used to discharge the capacitors.

The individual electronic circuits of Fig. 2 are shown in Fig. 3. The first circuit, shown in Fig. 3(a), is used to control the MOSFET of Fig. 1. First, it provides galvanic isolation by means of an optocoupler and second, it reproduces the control signal converting a PWM signal into the corresponding 
analogue voltage as illustrated in Fig. 3(a). The circuit shown in Fig. 3(b) is used to control the IGBT1 of Fig. 1 also providing galvanic isolation for the pulse needed for each single tracing of the I-V and $\mathrm{P}-\mathrm{V}$ characteristics. The circuit of Fig. 3(c) is used for current and voltage isolated measurement of the PV module or string. It uses two HCPL7800 isolation amplifiers followed by simple differential amplifiers. The isolated output voltage and current signals are sampled by a DAQ board to trace the I-V and $\mathrm{P}-\mathrm{V}$ characteristics using a laptop and virtual instruments developed in a LabVIEW application.

As can be seen from Fig. 1 (with the jumper in position A) the MOSFET drain current and the PV module current $\left(I_{P V}\right)$ are the same. Therefore, the operating point is given by the intersection of the PV module characteristic with the MOSFET one for a given voltage $V_{G S}$. While $V_{G S}$ is less than the threshold voltage $V_{t h}$, the MOSFET will be OFF. When $V_{G S}$ is increased above $V_{t h}$, the device will operate in its active region where the drain current rises linearly with $V_{G S}$. Thus, by sweeping $V_{G S}$ with a suitable signal the operating point of the MOSFET sweeps the $\mathrm{I}_{\mathrm{PV}}-\mathrm{V}_{\mathrm{PV}}$ characteristic between $V_{O C}$

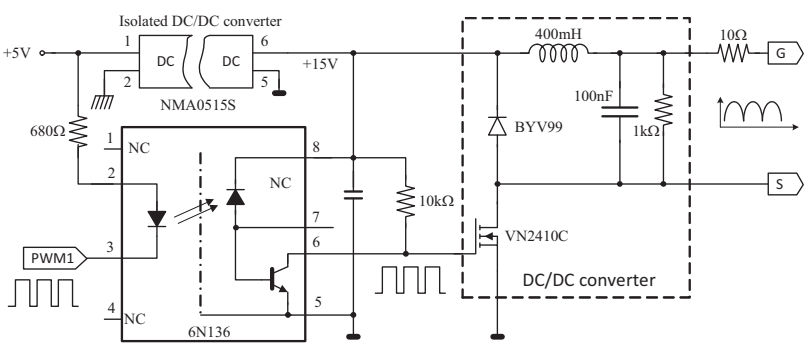

(a)

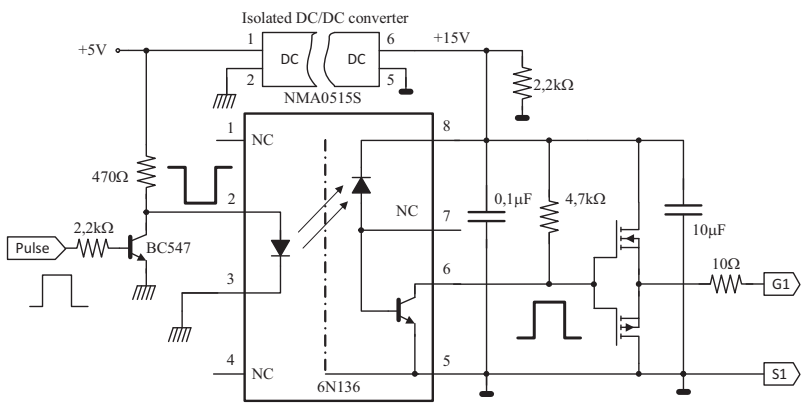

(b)

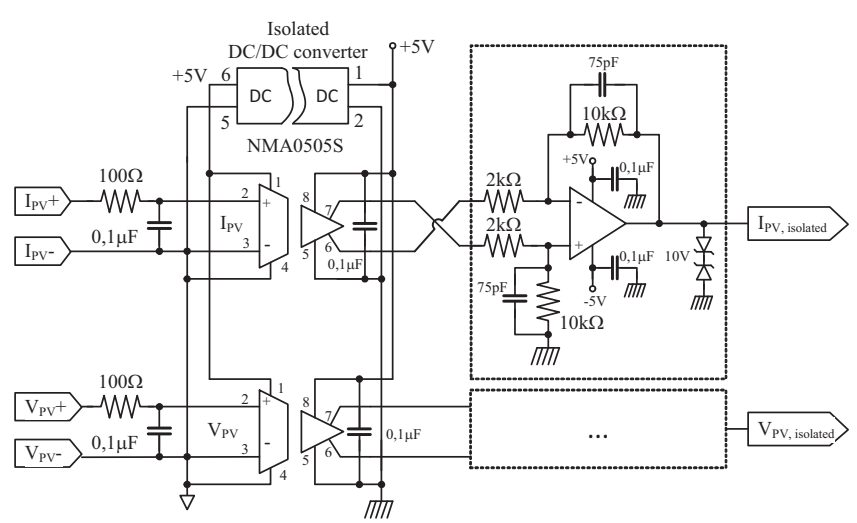

(c)

Fig. 3. Individual electronic circuits providing galvanic isolation: (a) $\mathrm{DC} / \mathrm{DC}$ converter for the conversion of the digital pulses into the corresponding MOSFET voltage control; (b) IGBT driver for I-V and P-V tracing of strings; (c) Current and voltage measurement circuit. and $I_{S C}$ [5]. For PV modules and when only is available an oscilloscope, this $V_{G S}$ voltage is generated through the circuit shown in Fig. 4(a) which is a precision rectifier with a suitable gain and a variable positive DC offset voltage. The input is a low frequency sinusoid generated by the oscillator shown in Fig. 4(b) based on the MAX038. However, when a DAQ system is available, the LabVIEW application developed in this work replaces these two circuits of figures 4(a) and 4(b).

The output voltage of Fig. 4(a) is the reference of the control voltage $V_{G S}$ that controls the MOSFET of Fig. 1. This voltage is converted into pulses with a duty cycle proportional to its amplitude. This is done by using a PWM circuit built with the comparator $\mathrm{C}$ of Fig. 4(d) and the sawtooth generator shown in Fig. 4(c) which is based on the NE555 and generates a sawtooth carrier with a frequency of $11 \mathrm{kHz}$. The galvanic isolation of the digital pulses is made by the optocoupler 6N136. Galvanic isolation and is particularly important when the voltage across the PV module and the output current are to be measured with a digital acquisition system or when a PV string is to be tested instead of a module as it is also the case in this work.

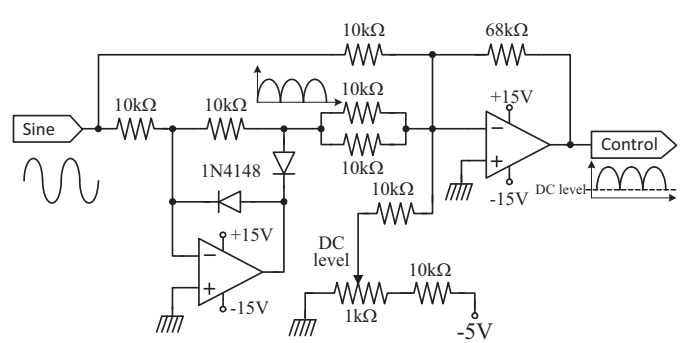

(a)

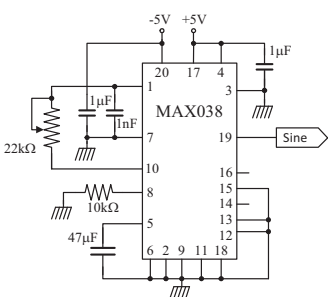

(b)

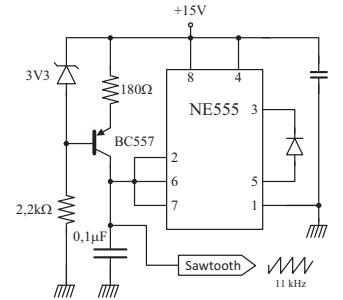

(c)

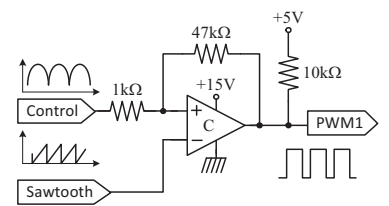

(d)

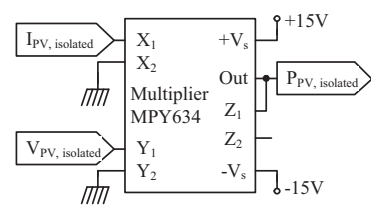

(e)

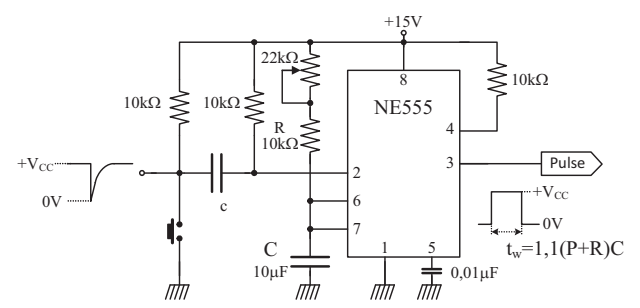

(f)

Fig. 4. Auxiliary electronic circuits: (a) Sweeping voltage $V_{G S}$ for continuous tracing of PV modules; (b) Sinusoidal generator; (c) Sawtooth generator; (d) PWM circuit; (e) Multiplier and (f) Pulse generator. 
The digital pulses are converted again into an analogue voltage by means the DC/DC converter shown in Fig. 3(a). This voltage corresponds to the voltage $V_{G S}$ that will control the MOSFET of Fig. 1 producing a proportional drain current which is the same of the PV module.

For tracing the I-V and P-V characteristics of high voltage PV strings, the part of the circuit of Fig. 1 including the two IGBTs and the capacitors, is jointly used with the control circuit of Fig. 3(b). A single pulse is generated for each I-V tracing. The pulse wide is adjusted to $100 \mathrm{~ms}$ and corresponds to the time the IGBT1 is turned on. This pulse has to be longer enough to guarantee a complete sweep from open circuit to short circuit condition which depends on the voltage, current and capacity. The acquisition of voltage and current of the PV string is achieved during this period of time, by using the DAQ board, and the I-V and P-V characteristics are plotted on a XY graph using the developed LabVIEW application. Furthermore, other parameters such as the MPP, $I_{M P P}, V_{M P P}, V_{O C}, I_{S C}$ and form factor are also plotted. Nevertheless if only a digital oscilloscope is available, the pulse is generated by using the electronic circuit of Fig. 4(f). On the other hand, the output current and voltage of Fig. 3(c) are multiplied by the analogue multiplier MPY634, as shown in Fig. 4(e), to also trace the P-V characteristics.

In conclusion, it is clear that all electronic circuits are based on simple, widely used and low-cost components.

\section{THE DEVELOPED LABVIEW APPLICATIONS}

This section presents a powerful and flexible alternative to the setup based on an oscilloscope. This alternative is based on a low-cost DAQ system which enhances the functionalities of the I-V tracer. This DAQ system is based on the NI-USB 6008 data acquisition board, a laptop and two applications developed in LabVIEW with interfaces based on virtual instruments. Besides the same functionalities obtained by means of an oscilloscope, either in YT or in XY mode, the new setup can easily provide very important parameters such as $V_{O C}, I_{S C}, V_{M P P}, I_{M P P}$ and form factor. Furthermore, all the acquired data can be saved for future digital processing and analysis.

The first LabVIEW application and its interface, named "I$\mathrm{V}$ and P-V characteristic: PV modules", is shown in Fig. 5(a) and allows tracing the I-V and P-V characteristics of modules used in typical grid connected PV systems. In this case the PWM control signal is generated by the LabVIEW application instead of the analogue circuit shown in Fig. 4(a). Thus the circuits of figures 4(a) and 4(b) are no longer needed. The control signal is generated by using an analogue output of the USB data acquisition board with a frequency of about $2 \mathrm{~Hz}$, with 200 points per cycle. However, these parameters can be programmed by the user. Next, the electronic circuits shown in figures 4(d) and 3(a) are used as described previously to obtain the same control signal, but with galvanic isolation, to drive the MOSFET of Fig. 1.

The acquisition of the isolated signals of voltage and current is carried out via two input channels of the data acquisition board with a sample rate of $5 \mathrm{kS} / \mathrm{s}$. The control signal is generated when the application is run and, simultaneously, the acquisition of the signals of voltage and current is initiated. Then, the graphical representation of the
$\mathrm{I}-\mathrm{V}$ and $\mathrm{P}-\mathrm{V}$ curves is made and the main parameters of the PV module are calculated. This procedure is continuously done.

The second LabVIEW interface, named "I-V and P-V characteristics: PV strings", is shown in Fig. 5(b) and is used to trace the $\mathrm{I}-\mathrm{V}$ and $\mathrm{P}-\mathrm{V}$ characteristics of PV strings. In this case, the pulse needed to drive the IGBT1 as an electronic switch is generated by the application and the USB DAQ board replacing, in this way, the electronic circuit of Fig. 4(f). The duration of this pulse can be programmed by the user and the default value is $200 \mathrm{~ms}$. After being initialized the acquisition, this pulse is generated and sent to the input of the electronic circuit of Fig. 3(b) by using a digital output of the USB DAQ board. This circuit provides galvanic isolation and turns on the IGBT1 and thus starts the charge of the capacitors. Since these capacitors are initially discharged through the IGBT2 the current measured for zero voltage corresponds to the short circuit current $\left(I_{S C}\right)$ of the PV string. The duration of pulse must be enough to charge completely the capacitors up to the open circuit voltage $\left(V_{O C}\right)$. The acquisition finishes at the end of the pulse and, then, the capacitors can be discharged again through the IGBT2 in order to be ready for another charging cycle.

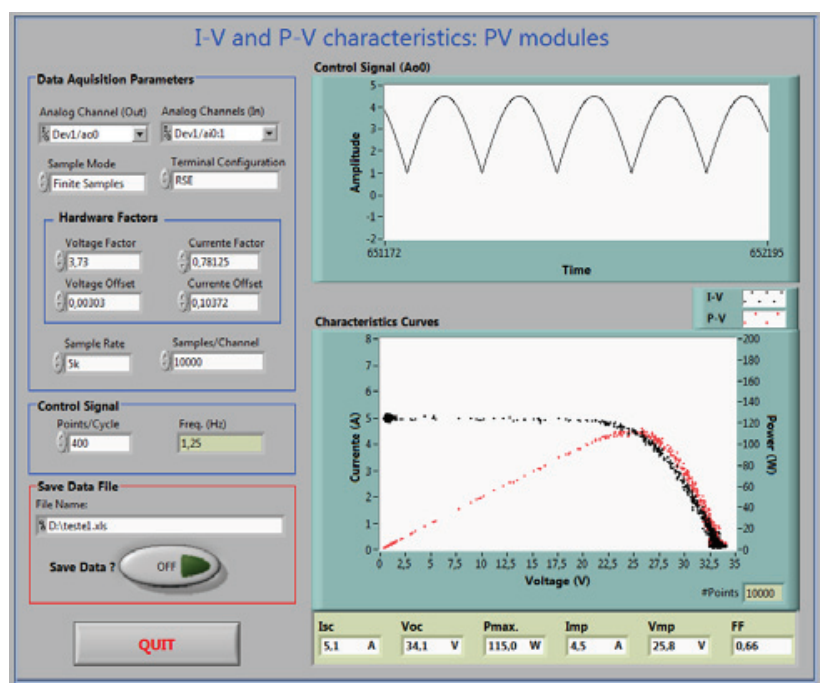

(a)

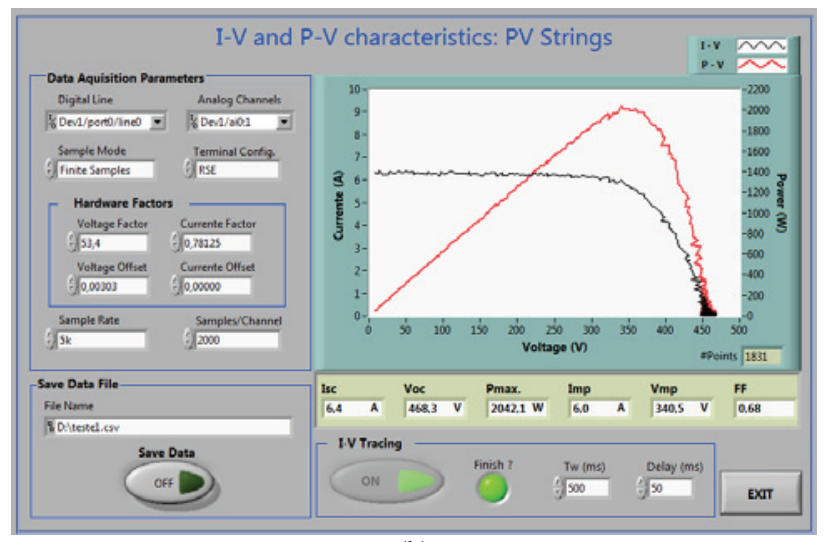

(b)

Fig. 5. User Interfaces for tracing the I-V and P-V characteristics of: (a) PV modules; (b) PV strings. 


\section{EXPERIMENTAL RESULTS}

In order to evaluate the performance of the proposed electronic instrument, it was used a flexible and configurable set of nine PV modules, shown in Fig. 6(a), with the following parameters at Standard Test Conditions (STC: cell temperature of $25^{\circ} \mathrm{C}$ and irradiance of $1000 \mathrm{~W} / \mathrm{m}^{2}$ with air mass of 1.5): $220 \mathrm{~W}, V_{O C}=36.76 \mathrm{~V}, I_{S C}=8.30 \mathrm{~A}$, $V_{M P P}=29.38 \mathrm{~V}$ and $I_{M P P}=7.51 \mathrm{~A}$ with 60 cells in series. It can be used just a single PV module or they can be connected in strings of 3, 5, 7 and 9 modules, or up to 4 strings of 2 modules can be connected in parallel, as shown in Fig. 6(b). Also the $16 \mathrm{PV}$ modules mounted on the solar tracker shown in Fig. 6(c) have been used in the tests achieved in this work. These modules have the following parameters at STC: $190 \mathrm{~W}, \quad V_{O C}=32.5 \mathrm{~V}, \quad I_{S C}=8.08 \mathrm{~A}, \quad V_{M P P}=26.1 \mathrm{~V} \quad$ and $I_{M P P}=7.28 \mathrm{~A}$, with 54 cells in series. Thus, the voltage parameters of the PV string are: $V_{O C}=520 \mathrm{~V}$ and $V_{M P P}=417.6 \mathrm{~V}$.

The experimental results presented below have been obtained with a single PV module and two different PV strings:

- String 1: 9 PV modules FTS-220P with total $V_{O C}=330.84 \mathrm{~V}$ and $I_{S C}=8.30 \mathrm{~A}$ (at STC);

- String 2: 16 PV modules KC190GHT-2 with total $V_{O C}=520 \mathrm{~V}$ and $I_{S C}=8.08 \mathrm{~A}$ (at STC).

Because of the high voltages, two electrolytic capacitors BHC Aerovox with $1000 \mu \mathrm{F}$ and $400 \mathrm{~V}$ were connected in series $\left(C_{1}\right.$ and $C_{2}$ shown in Fig. 1).

The output voltage $\left(V_{P V}\right)$ is sensed using the voltage divider $\mathrm{R}_{\mathrm{P}}$ and $\mathrm{R}_{\mathrm{Vpv}}$, shown in Fig. 1 , and the output current $\left(I_{P V}\right)$ is measured using the sensing resistor $\mathrm{R}_{\mathrm{Ipv}}$. The voltages across $\mathrm{R}_{\mathrm{Vpv}}$ and $\mathrm{R}_{\mathrm{Ipv}}$ are amplified by means of the isolation and differential amplifiers shown in Fig. 8. The scale factors are the following: $0.78125 \mathrm{~A} / \mathrm{V}$ for $I_{P V}$ and $3.73 \mathrm{~V} / \mathrm{V}$ for $V_{P V}$ of a single module and $53.4 \mathrm{~V} / \mathrm{V}$ for $V_{P V}$ of PV strings.

Fig. 7 shows the I-V and P-V tracing of the PV module FTS-220P characteristics, under the effect of shadow, using the interface of Fig. 5(a). Fig. 7(a) illustrates the 60 cells and bypass diodes of the PV module and figures 7(b), 7(c) and $7(d)$ show the effect on the characteristics when the cells 10 , $10+11$ and $10+11+30$ are shadowed, respectively.

The characteristics without shadow have been shown in Fig. 5(a). When cell 10 is shadowed, the string formed by cells 1 to 20 is bypassed since the first bypass diode turns on immediately. Consequently, even the string output current is the same there is a drop voltage of $10 \mathrm{~V}$, as shown in Fig. 7(b), which corresponds to a voltage drop of $0.5 \mathrm{~V}$ in each cell. As expected the power is about half of the initial value. Figures 7(b) and 7(c) are similar since cells $10+11$ belong to the same string of cells. However, when also cell 30 is shadowed, the string formed by cells 21 to 40 is bypassed by the second bypass diode, and the current flows through cells 41 to 60 . Of course, in this case the power is strongly reduced.

In Fig. 8 the LabVIEW application was used for monitoring the effect of shadow due to a small wind turbine on the PV string 1. Some photos were taken during one hour and are also shown in Fig. 8. Fig. 9(a) shows the PV string characteristics at 11:55, after the shadow has passed. Fig. 9(b) shows the characteristics of the PV string 2 which were obtained on the same day at about 14:05. The radiation was $897 \mathrm{~W} / \mathrm{m}^{2}$, the ambient temperature was $27.5^{\circ} \mathrm{C}$, and the modules temperature was $60.1^{\circ} \mathrm{C}$. In Fig. 10 the digital oscilloscope Tektronix TDS1001B and the electronic circuits of figures 4(f), 3(b), 3(c) and 4(e) were used for monitoring the PV string 2.

\section{CONCLUSIONS}

This paper presents a robust instrument for monitoring and processing voltage and current of PV modules and high voltage PV strings, by tracing their $\mathrm{I}-\mathrm{V}$ and $\mathrm{P}-\mathrm{V}$ characteristics on an oscilloscope. All electronic circuits are based on simple, low-cost and widely used components. For monitoring the characteristics of PV modules a power MOSFET is used as an electronic fast varying load. The MOSFET is controlled by means of an optimized sweeping gate-source voltage, which consists of a rectified sinusoid with variable DC level for different threshold voltages. For monitoring the characteristics of high voltage PV strings, an IGBT and two series connected capacitors were used. A second IGTB was used to discharge the capacitors through a power resistor. The electronic instrument includes galvanic isolation, to avoid damage of the data acquisition system, and to improve the safety of the operator, mainly in case of high voltage string tests. As an alternative to the oscilloscope, two LabVIEW applications have been developed in order to offer additional processing features and flexibility. For this purpose a low-cost USB DAQ board was used. Extensive experimental tests with several PV modules and strings were

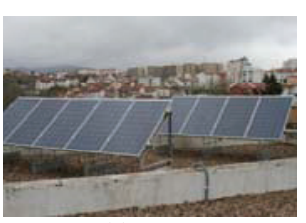

(a)

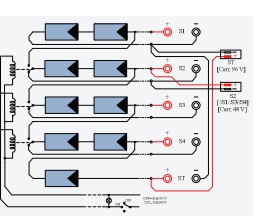

(b)

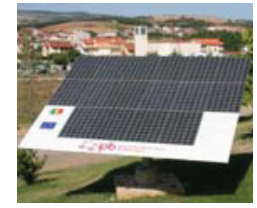

(c)
Fig. 6. PV strings used to obtain the experimental results.

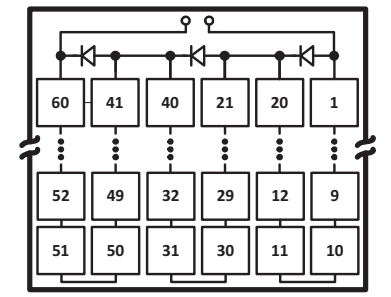

(a)

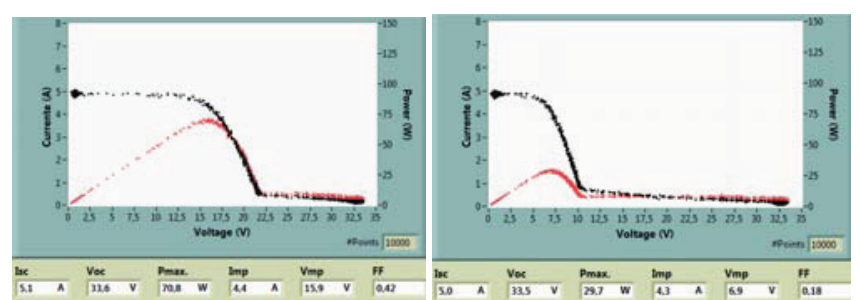

(c)

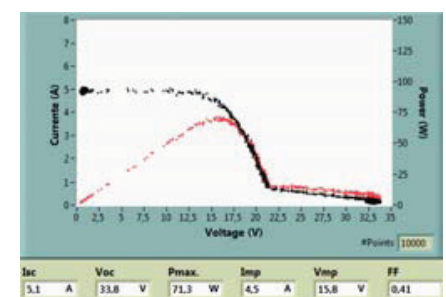

(b)

(d)
Fig. 7. I-V (black) and P-V (red) characteristics: (a) PV module layout; (b) Cell 10 shadowed; (c) Cells 10+11 shadowed; (d) Cells $10+11+30$ shadowed. 

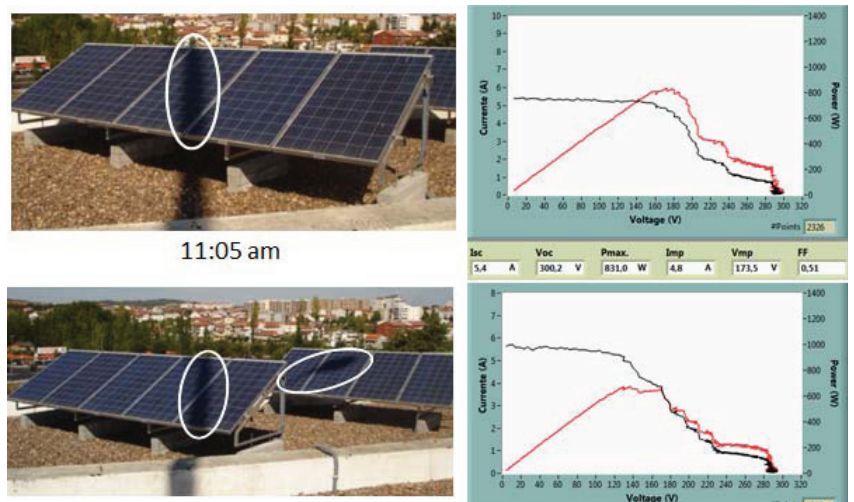

$11: 15 \mathrm{am}$

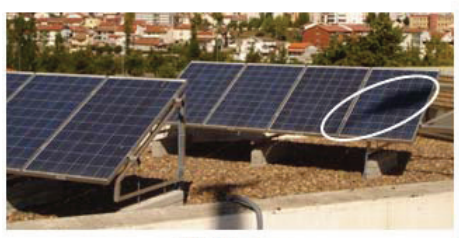

$11: 37 \mathrm{am}$
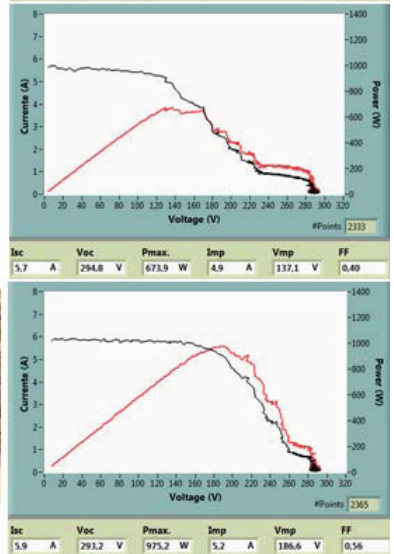

Fig. 8. Effect of shadow of a small wind turbine on the PV string 1.

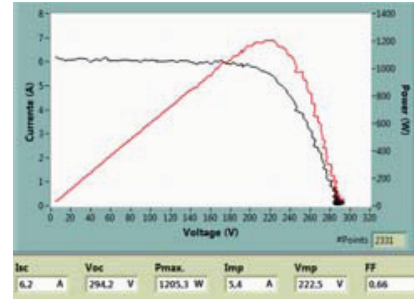

(a)

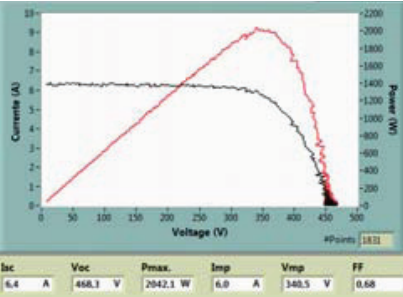

(b)
Fig. 9. I-V and P-V characteristics of PV strings: (a) String 1; (b) string 2.

carried out in real field conditions. The results demonstrate the usefulness and robustness of the proposed electronic instrument as well as the LabVIEW applications, developed for this work. The proposed instrument is suitable to be used in analysing the influence of field conditions, like temperature, irradiance and partial shadowing, on PV modules and on PV strings performance, as well as in identifying degradation and malfunction conditions.

\section{REFERENCES}

[1] IEA-PVPS, "Trends in Photovoltaic Applications - Survey report of selected IEA countries between 1992 and 2012", Report IEA-PVPS T123:2013, [Online] Available: www.iea-pvps.org/index.php?id=trends.

[2] EPIA and Greenpeace, "Solar Generation 6 - Solar photovoltaic electricity empowering the world: 2011", [Online] Available: http://www.epia.org/news/publications.

[3] E.L. Meyer and E.E. Van Dyk, "Assessing the Reliability and Degradation of Photovoltaic Module Performance Parameters", IEEE Trans. Rel., Vol. 53, N. ${ }^{\circ}$ 1, pp. 83-92, March 2004.

[4] E.E. Van Dyk, A.R. Gxasheka, E.L. Meyer, "Monitoring CurrentVoltage Characteristics and Energy Output of Silicon Photovoltaic Modules", ELSEVIER, Renewable Energy 30, pp. 399-411, 2005.

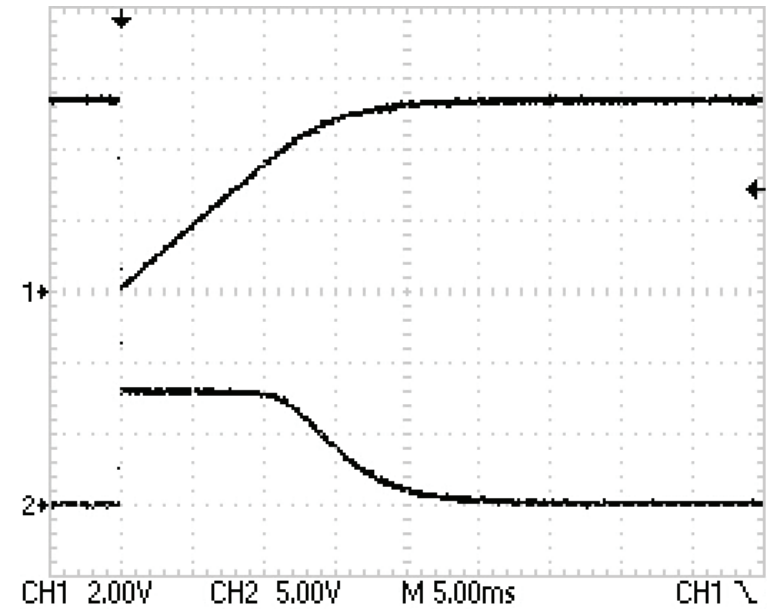

(a)

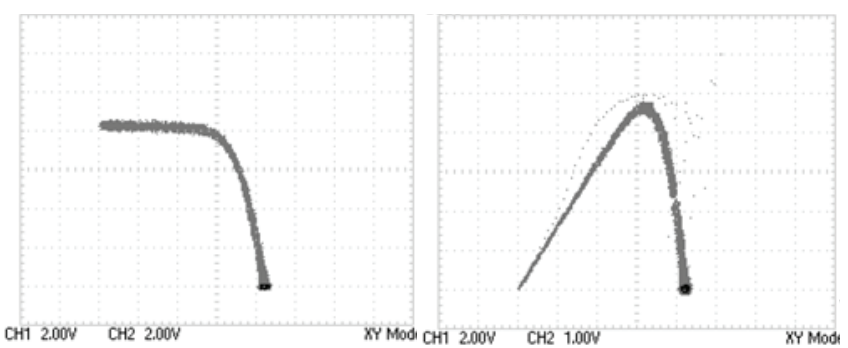

(b)

(c)

Fig. 10. PV string 2: (a) Voltage (ch1) and current (ch2) using the oscilloscope in YT mode; (b) I-V characteristics in XY mode; (c) $\mathrm{P}-\mathrm{V}$ characteristics in $\mathrm{XY}$ mode.

[5] V. Leite, F. Chenlo, "An Improved Electronic Circuit for Tracing the I-V Characteristics of Photovoltaic Modules and Strings", in Proc. International Conference on Renewable Energies and Power Quality, March 23-25, 2010.

[6] V. Leite, J. Batista, F. Chenlo, J. Afonso "Low-Cost Instrument for Tracing Current-Voltage Characteristics of Photovoltaic Modules", in Proc. International Conference on Renewable Energies and Power Quality, March 28-30, 2012.

[7] A. Garrigós and J. Blanes, "Power MOSFET is Core of Regulated-DC Electronic Load”, EDN, pp. 92-93, March 17, 2005.

[8] Y. Kuai and S. Yuvarajan, "An Electronic Load for Testing Photovoltaic Panels", ELSEVIER, Journal of Power Sources 154, pp. 308-313, 2006.

[9] F. Recart, H. Mäckel, A. Cuevas and R. A. Sinton, "Simple Data Acquisition of the Current-Voltage and Illumination Voltage Curves of Solar Cells", in Proc. 4th World Conference on Photovoltaic Energy Conversion, May 2006, Vol. 1, pp. 1215-1218.

[10] F. De Lia, S. Castello and L. Abenante, "Efficiency Degradation of CSilicon Photovoltaic Modules After 22-Year Continuous Field Exposure", in Proc. 3rd World Conference on Photovoltaic Energy Conversion, May 2003, pp. 2105-2108.

[11] J. J. M. Ibirriaga, X. M. M. Pena, A. O. D. Sera, R. Teodorescu, "Lowcost, high flexibility I-V curve tracer for photovoltaic modules", in Proc. 12th International Conference on Optimization of Electrical and Electronic Equipment, May 20 - 22, 2010, pp 1210-1215.

[12] E. E. Van Dyk, A. R. Gxasheka, E.L.Meyer, "Monitoring CurrentVoltage Characteristics of Photovoltaic Modules", in Proc. 29th IEEE Photovoltaic Specialists Conference, 2002, pp. 1516-1519. 